\title{
Integrally calcified solitary fibrous tumor in the retroperitoneum: a case report and review of the literature
}

\author{
Takehiro Maki ${ }^{* *}$, Syotaro Fujino ${ }^{1}$, Kenjiro Misu' ${ }^{1}$, Hiroyuki Kaneko ${ }^{1}$, Hitoshi Inomata', Makoto Omi ${ }^{1}$,
} Masatoshi Tateno ${ }^{2}$ and Kazuyoshi Nihei ${ }^{1}$

\begin{abstract}
Solitary fibrous tumor (SFT) is a rare stromal neoplasm and usually occurs in the thoracic cavity. We here report a case of retroperitoneal SFT with prominent calcification. A 64-year-old man presented with an incidentally detected retroperitoneal mass in the right upper abdomen. Imaging tests indicated an integrally calcified mass. The lesion was observed for 2 years and laparoscopically resected according to the patient's wish. Microscopically, the mass was mostly occupied by calcification and proliferous spindle cells were scattered with positive CD34 expression. We diagnosed morphologically benign SFT and the patient remained disease-free 1 year after the excision. There has been no report of such integrally calcified SFT. Retroperitoneal SFT is difficult to make a preoperative diagnosis, and careful follow-up after the excision is recommended because morphological malignancy does not always correspond to clinical malignancy.
\end{abstract}

Keywords: Solitary fibrous tumor, Retroperitoneum, Calcification

\section{Background}

Solitary fibrous tumor (SFT) is known as an uncommon mesenchymal neoplasm. It mainly develops in thoracic cavity but extrathoracic SFTs have been also reported. We here present a rare case of retroperitoneal SFT with marked calcification, followed by a review of the literature.

\section{Case presentation}

A 64-year-old Japanese man without any symptoms had a medical checkup, and abdominal ultrasonography revealed a mass of the right upper abdomen with acoustic shadow. He had hypertension and underwent appendectomy for appendicitis by McBurney's incision at 13 years old. He was $162 \mathrm{~cm}$ tall and weighted $70 \mathrm{~kg}$ (body mass index, 26.8). His blood pressure, pulse, oxygen saturation, and body temperature were 146/ $76 \mathrm{mmHg}, 66$ beats $/ \mathrm{min}, 97 \%$, and $36.2{ }^{\circ} \mathrm{C}$, respectively. His abdomen was flat and soft without any

\footnotetext{
* Correspondence: qwerty75568@yahoo.co.jp

${ }^{1}$ Department of Surgery, Kushiro Red Cross Hospital, 21-14, Shineichyo,

Kushiro, Hokkaido 085-8512, Japan

Full list of author information is available at the end of the article
}

palpable masses. Laboratory examinations revealed no remarkable abnormalities of complete blood count, inflammation, liver function, renal function, electrolytes, or coagulation system. Plain computed tomography showed a mass with extremely high densities; it was $6.5 \mathrm{~cm}$ in the longest diameter and located next to the undersurface of the right hepatic lobe and the right kidney (Fig. 1a, b). Contrast enhanced computed tomography did not reveal any other lesions in the chest and abdomen. Magnetic resonance imaging showed low signal intensities on both T1- and T2-weighted images (Fig. 1d, e). We considered that the lesion mainly consisted of calcification and diagnosed large peritoneal pearl body or sponge-induced granuloma due to the past appendectomy. Malignant fibrous histiocytoma, dedifferentiated liposarcoma, or extraskeletal osteosarcoma were considered as differential diagnoses although they were atypical or rare according to the imaging findings. We informed the patient about a low possibility of malignancy of the lesion and he wished observation. Two years after, the patient hoped surgical excision although the lesion showed a stable imaging in computed tomography (Fig. 1c). 


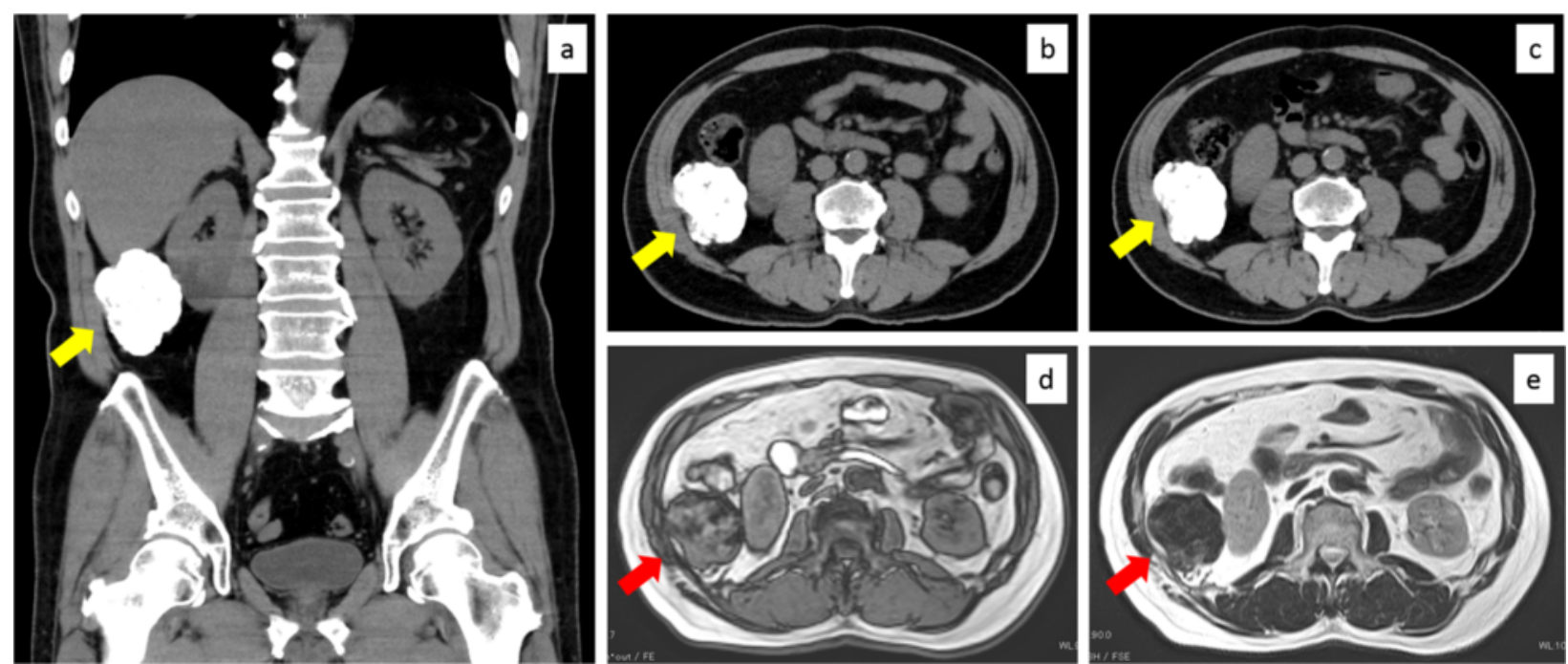

Fig. 1 Preoperative images. a, b Images of plain computed tomography on the patient's first visit. A mass with extremely high densities was located next to the undersurface of the right hepatic lobe and the right kidney (yellow arrows). It was $6.5 \mathrm{~cm}$ in the longest diameter. c An image of plain computed tomography 2 years after the patient's first visit (yellow arrow). There were no remarkable changes of the mass in its appearance or size. $\mathbf{d}$, e Magnetic resonance imaging on the patient's first visit. The mass showed low signal intensities on both d T1- and e T2-weighted images (red arrows)

We performed laparoscopic resection of the mass. We broke up adhesions between the omentum and the right upper abdominal wall and found a white and hard mass in the retroperitoneum over the adhesions (Fig. 2a). It was excised from the retroperitoneum using ultrasonically activated scalpel. Operative duration was $115 \mathrm{~min}$ and intraoperative hemorrhage was little. On gross examination, the excised specimen entirely looked like calcification (Fig. 2b). Division surface of the specimen mainly presented calcification and partially red soft tissues (Fig. 2c). Microscopically, small quantities of densely proliferated spindle cells were scattered in major quantities of hyalinizing collagen fiber (Fig. 3a). The spindle cells showed low cytological atypia and no mitosis. Immunohistochemistry showed positive staining of CD34 and vimentin and negative staining of Bcl-2, SMA, A-100, or p53 (Fig. 3b-g). Immunoreaction for Ki-67 was detected in fewer than $1 \%$ of the neoplastic
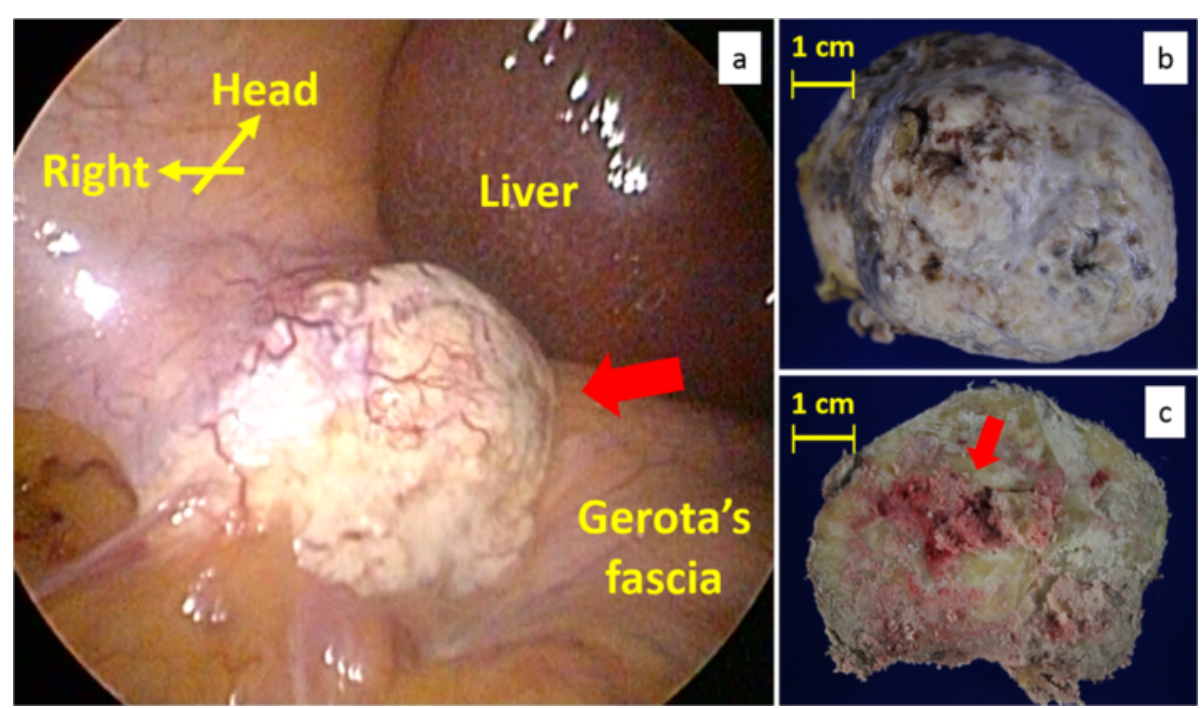

Fig. 2 A laparoscopic image of the right upper abdomen and photographs of the excised specimen. a In the right upper retroperitoneum, a white and hard mass was observed next to the right hepatic lobe and the right kidney. $\mathbf{b}$ The excised specimen presented calcified mass. c Division surface of the specimen presented mainly calcification and partially red soft tissues 


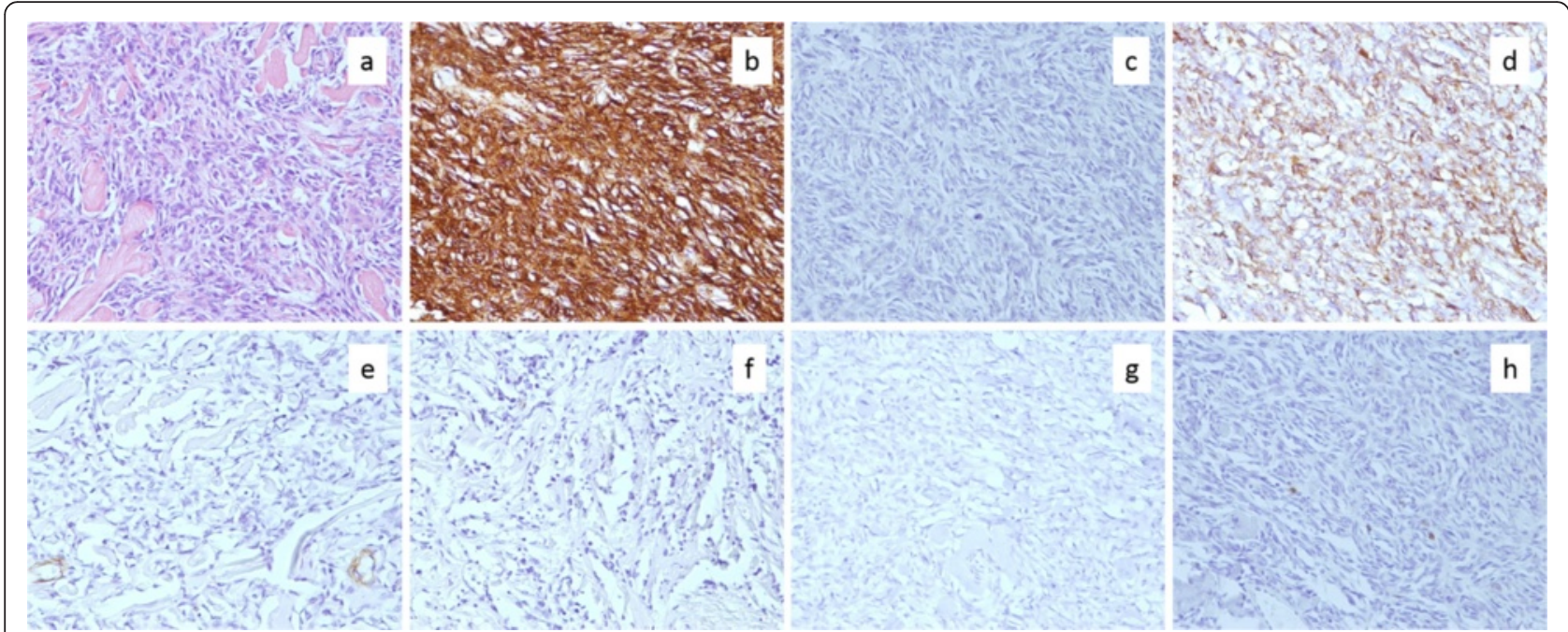

Fig. 3 Microscopic findings of the specimen. a An image of hematoxylin-eosin staining. Spindle cells with low cytological atypia densely proliferated in much hyalinizing collagen fiber. b-h Images of immunoreactivity for CD34, Bcl-2, vimentin, SMA, S-100, p53, and Ki-67 are shown, respectively

cells (Fig. 3h). The surgical margin was free from the tumor cells. We diagnosed morphologically and immunologically benign SFT in the retroperitoneum. The patient recovered without any postoperative complications, discharged 9 days after the surgery, and had no recurrence 1 year after the surgery.

SFT which is currently known as an uncommon soft tissue neoplasm was first reported as a kind of pleural neoplasms in 1931 [1] and was originally an exclusive diagnosis of pleural neoplasms [2]. Recent electron microscopic and immunohistochemical studies revealed that SFT derives from fibroblastic or myofibroblastic cells under the mesothelium [3, 4]. Thoracic SFT has an age-standardized incidence rate of 1.4 per million, typically occurs in the sixth and seventh decade, and affects both genders equally $[5,6]$. Eighty percent of SFT occurs in the thoracic cavity while $20 \%$ of that is found in extrathoracic regions including the retroperitoneum $[7,8]$. Retroperitoneal SFT as in the present case is considered to be comparatively rare.

SFT can cause local pressure syndrome [9] and some reports described that SFT presented hypoglycemia due to the insulin-like growth factor II secretion from the tumor $[10,11]$. In imaging studies, SFT typically presents welldefined and lobulated mass with well-enhancement [9]. Wignall et al. investigated characteristics of radiologic findings in 34 SFTs and revealed that $62 \%$ of them had the lobulated contours, $9 \%$ had the local invasions, $79 \%$ had heterogenous enhancement patterns, and $65 \%$ had strong contrast enhancement [12]. On magnetic resonance imaging, SFT typically exhibits hypoor isointensity in T1-weighted image and heterogeneous hyperintensity in T2-weighted image [13], the differential diagnoses of SFT in the retroperitoneum include liposarcoma, leiomyosarcoma, lymphoma, schwannoma, neurofibroma, leiomyoma, myolipoma, angiomyolipoma, sympathetic paraganglioma, desmoid tumor, and epithelioid sarcoma [14]. In the present case, SFT was incidentally detected without any symptoms, imaging inspection provided extremely atypical findings as any retroperitoneal neoplasms including SFT, and thus a precise preoperative diagnosis was difficult. Non-neoplastic lesions such as peritoneal pearl body or foreign body granuloma due to retained surgical sponge in the past appendectomy were exclusively considered, but the imaging findings were not typical of them as well as of neoplastic disease [15]. Fine needle aspiration or biopsy might be difficult due to its marked calcification.

Microscopically, SFT shows multiplying spindle cells in the patternless appearance and the hemangiopericytomalike appearance with prominent vascularity [16]. England et al. described high cellularity, high mitotic activity (more than 4 mitoses per 10 high-power field), pleomorphism, necrosis, and hemorrhagic changes as the criteria for morphological malignancy of SFT [17]. Those malignant features are observed in about $10 \%$ of SFTs [18]. In immunohistochemistry, CD34 and Bcl-2 are especially useful for differentiating SFT from the other spindle cell neoplasia [9, 19]. Immunoreactivity for CD34 was observed in $98 \%$ and that for Bcl-2 was confirmed in $90 \%$ of SFTs [20]. Other immunological targets such as CD99, desmin, SMA, c-kit, S-100, EMA, CK, CD31, and inhibin are also used for specific diagnosis of SFT [21]. In the present case, the marked calcification was extremely unusual but the scattered tumor cells provided typical structures of SFT with positive immunostaining of CD34 and were considered to be morphologically benign. 
Table 1 Reported 31 cases of solitary fibrous tumor in the retroperitoneum

\begin{tabular}{|c|c|c|c|c|c|c|c|c|c|c|}
\hline \multirow[t]{2}{*}{ Reference } & \multirow[t]{2}{*}{ Age } & \multirow[t]{2}{*}{ Sex } & \multirow[t]{2}{*}{ Major complaint } & \multirow[t]{2}{*}{ Adjacent structure } & \multirow[t]{2}{*}{ Size $(\mathrm{cm})$} & \multirow{2}{*}{$\begin{array}{l}\text { Morphological } \\
\text { malignancy }\end{array}$} & \multicolumn{3}{|c|}{ Immunohistochemistry } & \multirow[t]{2}{*}{ Outcome } \\
\hline & & & & & & & $\overline{\mathrm{CD} 34}$ & $\mathrm{BCl}-2$ & $\mathrm{p} 53$ & \\
\hline \multirow[t]{2}{*}{ 2008, Takizawa [23] } & ND & M & Dysuria & ND & 9 & Benign & + & + & - & Disease-free \\
\hline & ND & M & Asymptomatic & Kidney & ND & Benign & + & + & - & Disease-free \\
\hline 2005, Cristi [21] & 28 & $\mathrm{~F}$ & Pain & Sacrum & 7.5 & Benign & + & + & ND & ND \\
\hline 2009, Lau [36] & 58 & $\mathrm{~F}$ & Asymptomatic & ND & 15 & Benign & + & + & ND & 7.3 years, disease-free \\
\hline 2011, Charhi [39] & 75 & M & Palpable mass & Pancreas tail and left adrenal grand & ND & Benign & + & + & ND & ND \\
\hline 2012, Azadi [41] & 57 & M & Asymptomatic & Pancreas & $\begin{array}{l}3.1 \text { and } \\
4.3\end{array}$ & Benign & + & + & ND & ND \\
\hline 2014, Toniato [18] & 54 & M & Severe hypertension & Bilateral adrenal grand & 15 and 4 & Benign & + & + & ND & 1.5 years, disease-free \\
\hline 2004, Kunieda [16] & 53 & M & Swelling & Right kidney & 14 & Benign & + & - & - & 3 years, disease-free \\
\hline $\begin{array}{l}\text { 2015, Maki [The present } \\
\text { case] }\end{array}$ & 64 & M & Asymptomatic & Liver and right kidney & 7.5 & Benign & + & - & - & 1 year, disease-free \\
\hline 2009, Trabelsi [35] & 55 & M & Urinary symptom & Bladder & 15 & Benign & + & - & ND & 5 years, disease-free \\
\hline 2000, Morimitsu [26] & 72 & $\mathrm{~F}$ & ND & Left kidney & 8 & Benign & + & ND & - & 10 months, disease-free \\
\hline 2001, Clayton [28] & 17 & $\mathrm{~F}$ & Hip pain & Spinal column & 15 & Benign & + & ND & ND & 4 years, disease-free \\
\hline 2004, Kume [30] & 47 & $\mathrm{~F}$ & Pulsating mass & Superior mesenteric artery & 4 & Benign & + & ND & ND & 1 year, disease-free \\
\hline 2008, Shin [34] & 56 & M & Asymptomatic & $\begin{array}{l}\text { Left external iliac artery and psoas } \\
\text { muscle }\end{array}$ & ND & Benign & + & ND & ND & 8 days, discharged \\
\hline 2011, Savas [40] & 60 & M & Pain & Right kidney & 4.5 & Benign & + & ND & ND & 1 year, disease-free \\
\hline 2013, Baldi [22] & 46 & $\mathrm{~F}$ & ND & ND & ND & Benign & ND & ND & ND & 13 years, metastasis (dead) \\
\hline \multirow[t]{2}{*}{ 2008, Takizawa [23] } & ND & $\mathrm{F}$ & Palpable mass & Left kidney & ND & Malignant & + & + & - & Disease-free \\
\hline & ND & M & Asymptomatic & ND & ND & Malignant & + & + & - & Disease-free \\
\hline 2007, Yamashita [33] & 69 & $\mathrm{~F}$ & Swelling & Right kidney & 14 & Malignant & + & + & ND & 2.2 years, disease-free \\
\hline 2011, Bae [38] & 59 & M & Asymptomatic & Gallbladder & 22 & Malignant & + & + & ND & 3 years, disease-free \\
\hline 2012, Hata [42] & 83 & M & ND & ND & 10 & Malignant & + & + & ND & $\begin{array}{l}4 \text { years, local recurrence (6 years, } \\
\text { alive) }\end{array}$ \\
\hline 2008, Ito [27] & 48 & $\mathrm{~F}$ & Leg edema & Left kidney & 5.5 & Malignant & + & - & + & 2.5 years, disease-free \\
\hline 2009, Nomura [37] & 27 & $\mathrm{~F}$ & $\begin{array}{l}\text { Palpable mass and } \\
\text { pain }\end{array}$ & Right latissimus dorsi muscle & 11 & Malignant & + & - & ND & 6 months, disease-free \\
\hline 2002, Nakatani [29] & 56 & $\mathrm{~F}$ & Palpable mass & Left kidney & 9 & Malignant & + & ND & ND & 2.3 years, disease-free \\
\hline 2015, Kim [9] & 52 & $\mathrm{~F}$ & Vaginal discharge & Sacrum & 12 & Malignant & + & ND & ND & 3 years, disease-free \\
\hline 2009, Mosquera [24] & 68 & $\mathrm{~F}$ & ND & ND & 20 & Malignant & - & ND & + & 1 month, dead of disease \\
\hline
\end{tabular}


Table 1 Reported 31 cases of solitary fibrous tumor in the retroperitoneum (Continued)

\begin{tabular}{|c|c|c|c|c|c|c|c|c|c|c|}
\hline 2004, Nagasako [31] & 81 & M & $\begin{array}{l}\text { lleus and palpable } \\
\text { mass }\end{array}$ & Pelvis & 18 & ND & + & + & ND & ND \\
\hline 2005, Yamaguchi [32] & 51 & $\mathrm{~F}$ & Pain & Left kidney & 10 & ND & + & + & ND & ND \\
\hline 2012, Aimé [20] & 58 & M & Palpable mass & Right kidney & 20 & ND & + & ND & ND & 1 year, disease-free \\
\hline 2013, Nogami [14] & 52 & $\mathrm{~F}$ & Emaciation & Pelvis & 36 & ND & + & ND & ND & Dead on arrival (autopsy case) \\
\hline 2013, Baldi [22] & 41 & M & ND & ND & ND & ND & ND & ND & ND & 23 years, local recurrence (dead) \\
\hline
\end{tabular}

The case order is sorted by morphological malignancy and findings of immunohistochemistry

$N D$ not described 
The problem regarding malignancy of SFT is discrepancies of morphological malignancy and clinical malignancy $[8,22,23]$. The discrepancy may be partially due to malignant transformation with dedifferentiation of the tumor cells $[24,25]$. Therefore, we should not trust morphological findings but immunohistochemistry for some relevant proteins may provide indications of SFT's clinical malignancy. Takizawa et al. reported that patients with positive immunostaining of both $\mathrm{CD} 34$ and $\mathrm{Bcl}-2$ had no recurrence [23]. Loss of immunoreactivity for CD34 and $\mathrm{Bcl}-2$ was observed in the component with malignant transformation [24, 25]. Immunoreaction for p53 was not observed in benign SFT but much confirmed in morphologically and clinically malignant SFT [25]. The present case morphologically yielded typical benign features without immunoreactivity for p53 but can potentially cause a recurrence and should be carefully followed up.

Almost all patients with SFT underwent surgical excision. Many surgical doctors recommend complete surgical excision to obtain clear margins with careful longterm follow-up $[8,9,16,26]$. There have been few reports concerning chemotherapy for SFT and thus its efficacy is not evident. Baldi et al. used anthracycline and ifosfamide for a patient with recurrent SFT and got partial response; cisplatin and gemcitabine, progressive disease [22]. We performed microscopically complete resection of the tumor and consider follow-up without adjuvant chemotherapy as reasonable.

SFT in the retroperitoneum is rare, and 31 cases have been reported including this case for the last 15 years $[9,14,16,18,20-24,26-42]$ (Table 1). The English language literature was extracted from PubMed from 2000 to 2015 using the following Medical Subject Heading terms: "solitary fibrous tumor" and "retroperitoneum". Age of onset ranged from 17 to 83 and its median was 56. Male to female ratio of the patients was 16:15. Ten patients (38\%) complained of local pressure symptoms in 26 patients with description of any symptoms; 9 patients (35\%), palpable mass; 7 patients (27\%), asymptomatic. Location of the tumor varied all over the retroperitoneal cavity. Size of the tumor ranged from 3.1 to $36 \mathrm{~cm}$ and its median was $11.5 \mathrm{~cm}$. No cases were preoperatively diagnosed as SFT. Surgical excision was performed in all cases. Morphologically, 16 cases (62 \%) presented benign features while 10 cases (38\%) exhibited malignant findings. Positive immunostaining for CD34, Bcl-2, and p53 was observed at 28 (97\%), 14 (74\%), and 2 (22 \%) in described 29, 19, and 9 cases, respectively. Clinical outcomes varied; 21 (78 \%) patients remained disease-free after the surgery, 4 patients (15\%) had local recurrence or distant metastasis after the operation, and 3 patients of them died of the disease. One case was diagnosed morphologically benign but suffered distant metastasis 13 years after the surgery and died. The only case of negative immunostaining for CD34 died of the disease. One of the 2 cases in which p53 was immunohistologically positive was dead of the disease. These results indicate that retroperitoneal SFT is quite difficult to diagnose and can be clinically malignant although morphological examinations yield benign findings and negative immunostaining of CD34 or positive immunostaining of p53 can be signs of clinical malignancy.

The present case showed prominent calcification in preoperative imaging and the excised mass mostly consisted of calcification with scattered tumor cells. Calcification is not rare for various neoplastic or non-neoplastic lesions in the retroperitoneum such as lipoma, liposarcoma, schwannoma, germ cell tumors, lymphoma after chemotherapy or radiotheraphy, and peritoneal pearl body [43, 44]. Nakashima et al. suggested that the absence of calcification can predict malignancy of primary retroperitoneal tumor [45]. In SFT, calcification was reported to be observed in 3 of 34 cases $(8.8 \%)$ [12] and regarded as an indicator of malignancy [46]. However, those kinds of calcification are tiny, scattered, or partial in the lesion. There has been no report of integrally calcified SFT like the present case. The reason why SFT coexisted with such significant calcification is not apparent but the fact is very interesting for considering carcinogenesis or nature of SFT.

\section{Conclusions}

We experienced a case of integrally calcified SFT in the retroperitoneum. There has been no report of SFT with such prominent calcification. Retroperitoneal SFT is difficult to diagnose preoperatively, and careful followup after the excision is crucial because morphological malignancy does not necessarily correspond to clinical malignancy.

\section{Consent}

Written informed consent was obtained from the patient for publication of this case report and any accompanying images. A copy of the written consent is available for review by the Editor-in-Chief of this journal.

Abbreviations

ND: not described; SFT: solitary fibrous tumor.

\section{Competing interests}

All authors have no competing interests.

\section{Authors' contributions}

TM and SF considered the present case based on the past literature and drafted the manuscript. KM was assigned to the patient and took the initiative in diagnosis and treatment for the patient. $\mathrm{HK}, \mathrm{HI}, \mathrm{MO}$, and $\mathrm{KN}$ participated in decision on therapeutic measures and consideration of the 
literature. MT made a pathological diagnosis. All authors read and approved the final manuscript.

\section{Authors' information}

$\mathrm{TM}, \mathrm{KM}, \mathrm{HK}, \mathrm{HI}, \mathrm{MO}$, and KN have qualification of medical specialists of Japan Surgical Society and belong to the Department of Gastroenterological Surgery II, Hokkaido University Graduate School of Medicine, North 15, West 7, Kita-ku, Sapporo, Hokkaido, 060-8638, Japan. MT has qualification of medical specialists of Japanese Society of Pathology.

\section{Acknowledgements}

Nobody is applied to acknowledgements.

\section{Author details}

${ }^{1}$ Department of Surgery, Kushiro Red Cross Hospital, 21-14, Shineichyo, Kushiro, Hokkaido 085-8512, Japan. Department of Pathology, Kushiro Red Cross Hospital, 21-14, Shineichyo, Kushiro, Hokkaido 085-8512, Japan.

\section{Received: 9 November 2015 Accepted: 11 February 2016} Published online: 13 February 2016

\section{References}

1. Klemperer P, Coleman BR. Primary neoplasms of the pleura. A report of five cases. Am J Ind Med. 1992;22:1-33.

2. Travis William D, Brambilia E, Muller-Hermelink HK, Harris CC. World Health Organization Classification of tumors. Pathology and genetics of tumors of the lung, pleura, thymus and heart. Lyon: IARC Press; 2004.

3. Said JW, Nash G, Banks-Schlegel S, Sassoon AF, Shintaku IP. Localized fibrous mesothelioma. An immunohistochemical and electron microscopic study. Hum Pathol. 1984;15:440-3.

4. Dervan PA, Tobin B, O'Conner M. Solitary (localized) fibrous mesothelioma. Evidence against mesothelial cell origin. Histopathology. 1986;10:867-75.

5. Thorgeirsson T, Isaksson HJ, Hardardottir H, Alfredsson H, Gudbjartsson T. Solitary fibrous tumors of the pleura: an estimation of population incidence. Chest. 2010;137:1005-6.

6. de Perrot M, Fischer S, Bründler MA, Sekine Y, Keshavjee S. Solitary fibrous tumors of the pleura. Ann Thorac Surg. 2002;74:285-93.

7. Vallat-Decouvelaere AV, Dry SM, Fletcher CD. Atypical and malignant solitary fibrous tumors in extrathoracic locations: evidence of their comparability to intra-thoracic tumors. Am J Surg Pathol. 1998;22:1501-11.

8. Hasegawa T, Matsuno Y, Shimoda T, Hasegawa F, Sano T, Hirohashi S. Extrathoracic solitary fibrous tumors: their histological variability and potentially aggressive behavior. Hum Pathol. 1999;30:1464-73.

9. Kim MY, Jeon S, Choi SD, Nam KH, Sunwoo JG, Lee JH. A case of solitary fibrous tumor in the pelvis presenting massive hemorrhage during surgery. Obstet Gynecol Sci. 2015;58:73-6.

10. Fukasawa Y, Takada A, Tateno M, Sato H, Koizumi M, Tanaka A, et al. Solitary fibrous tumor of the pleura causing recurrent hypoglycemia by secretion of insulin-like growth factor II. Pathol Int. 1998;48:47-52.

11. Maeda S, Sugita M, Sagawa M, Ueda Y, Sakuma T. Solitary fibrous tumor of the pleura suddenly induced hypoglycemia before surgical treatment. Ann Thorac Cardiovasc Surg. 2011;17:293-6.

12. Wignall OJ, Moskovic EC, Thway K, Thomas JM. Solitary fibrous tumors of the soft tissues: review of the imaging and clinical features with histopathologic correlation. Am J Roentgenol. 2010;195:W55-62.

13. Wakisaka N, Kondo S, Murono S, Minato H, Furukawa M, Yoshizaki T. A solitary fibrous tumor arising in the parapharyngeal space, with MRI and FDG-PET findings. Auris Nasus Larynx. 2009;36:367-71.

14. Nogami M, Hoshi T, Toukairin Y, Arai T, Uozaki H, Fukusato T. A case of the large retroperitoneal solitary fibrous tumor. Leg Med. 2013;15:19-22.

15. Turgut M, Akyüz O, Ozsunar Y, Kacar F. Sponge-induced granuloma ("gauzoma") as a complication of posterior lumbar surgery. Neurol Med Chir. 2005:45:209-11.

16. Kunieda K, Tanaka Y, Nagao N, Yamaguchi K, Sano J, Osada S, et al. Large solitary fibrous tumor of the retroperitoneum: report of a case. Surg Today. 2004;34:90-3

17. England DM, Hochholzer L, McCarthy MJ. Localized benign and malignant fibrous tumors of the pleura. A clinicopathologic review of 223 cases. Am J Surg Pathol. 1989;13:640-58.

18. Toniato A, Boschin IM, Pelizzo MR. A very rare bilateral adrenal tumor. Endocrine. 2014:45:502-3.
19. Goodlad JR, Fletcher CD. Solitary fibrous tumour arising at unusual sites: analysis of a series. Histopathology. 1991;19:515-22.

20. Aimé $A$, Lefèvre $J H$, Svrcek $M$, Terrier $P$, Tiret $E$, Balladur $P$. Solitary fibrous tumor of the retroperitoneum: case report and review of the literature. Jastrointest Cancer. 2012;43:226-30.

21. Cristi E, Perrone G, Battista C, Benedetti-Panici P, Rabitti C. A rare case of solitary fibrous tumour of the pre-sacral space: morphological and immunohistochemical features. In Vivo. 2005;19:777-80.

22. Baldi GG, Stacchiotti S, Mauro V, Dei Tos AP, Gronchi A, Pastorino U, et al. Solitary fibrous tumor of all sites: outcome of late recurrences in 14 patients. Clin Sarcoma Res. 2013;3:4

23. Takizawa I, Saito T, Kitamura Y, Arai K, Kawaguchi M, Takahashi K, et al. Primary solitary fibrous tumor (SFT) in the retroperitoneum. Urol Oncol. 2008;26:254-9.

24. Mosquera JM, Fletcher CD. Expanding the spectrum of malignant progression in solitary fibrous tumors: a study of 8 cases with a discrete anaplastic component-is this dedifferentiated SFT? Am J Surg Pathol. 2009;33:1314-21.

25. Yokoi T, Tsuzuki T, Yatabe $Y$, Suzuki M, Kurumaya $H$, Koshikawa $T$, et al. Solitary fibrous tumour: significance of p53 and CD34 immunoreactivity in its malignant transformation. Histopathology. 1998;32:423-32.

26. Morimitsu Y, Nakajima M, Hisaoka M, Hashimoto H. Extrapleural solitary fibrous tumor: clinicopathologic study of 17 cases and molecular analysis of the p53 pathway. APMIS. 2000;108:617-25.

27. Ito H, Fukuda M, Imamura $\mathrm{Y}$, Fuse $\mathrm{H}$. A malignant solitary fibrous tumor in the retroperitoneum. Int J Clin Oncol. 2008;13:173-5.

28. Clayton AC, Salomão DR, Keeney GL, Nascimento AG. Solitary fibrous tumor: a study of cytologic features of six cases diagnosed by fine-needle aspiration. Diagn Cytopathol. 2001;25:172-6.

29. Nakatani T, Tamada S, Iwai Y, Tanimoto Y. Solitary fibrous tumor in the retroperitoneum: a case with infiltrative growth. Hinyokika Kiyo. 2002:48:637-41.

30. Kume M, Komori K, Inoguchi H, Shoji T, Furuyama T, Sakamoto A, et al. Solitary fibrous tumor in the retroperitoneal space: report of a case. Surg Today. 2002;32:1099-101

31. Nagasako Y, Misawa K, Kohashi S, Sano H. Solitary fibrous tumor in the retroperitoneum. J Am Coll Surg. 2004;198:322-3.

32. Yamaguchi T, Takimoto T, Yamashita T, Kitahara S, Omura M, Ueda Y. Fatcontaining variant of solitary fibrous tumor (lipomatous hemangiopericytoma) arising on surface of kidney. Urology. 2005:65:175.

33. Yamashita S, Tochigi T, Kawamura S, Aoki H, Tateno H, Kuwahara M. Case of retroperitoneal solitary fibrous tumor. Hinyokika Kiyo. 2007;53:477-80.

34. Shin SS, Jeong YY, Kang HK. Myxoid solitary fibrous tumor of the retroperitoneum: MRI findings with the pathologic correlation. Korean J Radiol. 2008:9:279-82

35. Trabelsi A, Hammedi F, Rammeh S, Abdelkrim SB, Yacoub-Abid LB, Beïzig N, et al. Solitary fibrous tumor with giant multinucleated cells in the retroperitoneum—a case report. N Am J Med Sci. 2009;1:285-7.

36. Lau SK, Weiss LM, Chu PG. Myxoid solitary fibrous tumor: a clinicopathologic study of three cases. Virchows Arch. 2009;454:189-94.

37. Nomura T, Satoh R, Kashima K, Yamasaki M, Hirai K, Satoh F, et al. A case of large solitary fibrous tumor in the retroperitoneum. Clin Med Case Rep. 2009;2:21-5

38. Bae JM, Kim SW, Kim SW, Song SK. Malignant solitary fibrous tumor of retroperitoneum mimicking gastric submucosal tumor. Korean J Gastroenterol. 2011:57:47-50.

39. Charhi H, Bernoussi Z, Haddan A, Mesmoudi S, Elktaibi A, Mansouri F, et al. Primary solitary fibrous tumor of the retroperitoneum. Clin Pract. 2011;1:e137.

40. Savas M, Ciftci H, Ozgonul A, Sogut O, Guldur ME. An incidental solitary fibrous tumour in the retroperitoneum, coexisting with ipsilateral atrophic kidney. J Pak Med Assoc. 2011;61:909-11.

41. Azadi J, Subhawong A, Durand DJ. F-18 FDG PET/CT and Tc-99m sulfur colloid SPECT imaging in the diagnosis and treatment of a case of dual solitary fibrous tumors of the retroperitoneum and pancreas. J Radiol Case Rep. 2012:6:32-7.

42. Hata T, Tsuruta Y, Takamori S, Shishikura Y. Non-islet cell tumor hypoglycemia at the second recurrence of malignant solitary fibrous tumor in the retroperitoneum and pelvis: a case report. Case Rep Oncol. 2012;5:420-7.

43. Hayasaka K, Yamada T, Saitoh Y, Yoshikawa D, Aburano T, Hashimoto H, et al. CT evaluation of primary benign retroperitoneal tumor. Radiat Med. 1994;12:115-20 
44. Acar T, Harman M, Guneyli S, Gemici K, Efe D, Guler I, et al. Cross-sectional imaging features of primary retroperitoneal tumors and their subsequent treatment. J Clin Imaging Sci. 2015;5:24.

45. Nakashima J, Ueno M, Nakamura K, Tachibana M, Baba S, Deguchi N, et al. Differential diagnosis of primary benign and malignant retroperitoneal tumors. Int J Urol. 1997:4:441-6.

46. Li JP, Xie CM, Zhang R, Li H, Liu XW, Zhang Y, et al. Imaging features and clinicopathological manifestations of solitary fibrous tumors. Zhonghua Zhong Liu Za Zhi. 2010;32:363-7.

\section{Submit your manuscript to a SpringerOpen ${ }^{\circ}$ journal and benefit from:}

- Convenient online submission

- Rigorous peer review

- Immediate publication on acceptance

- Open access: articles freely available online

- High visibility within the field

- Retaining the copyright to your article

Submit your next manuscript at $>$ springeropen.com 